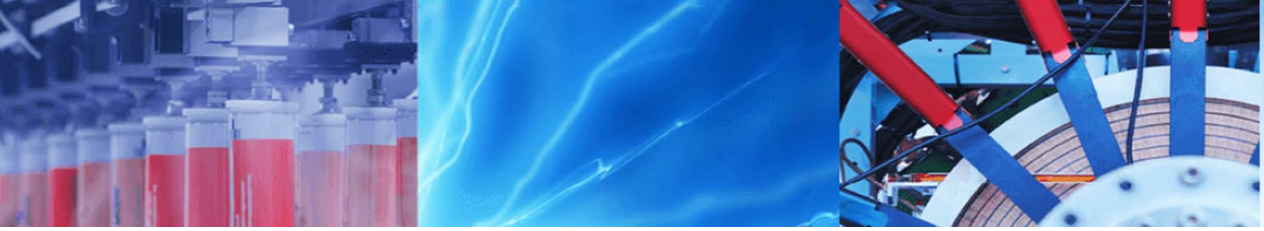

Research Article

\title{
Dyeing and flame retardant finishing of silk fabric: an ecofriendly approach
}

\author{
Goutam Bar ${ }^{1}$ Mahadev Bar ${ }^{2}$
}

Received: 3 June 2019 / Accepted: 28 January 2020 / Published online: 7 February 2020

(c) Springer Nature Switzerland AG 2020

\begin{abstract}
In the current context of environmental contamination due to disposal of textile-manufacturing waste, substitution of synthetic dyes and chemicals with bio-colour or bio-extract is a big confront. Thus, the need of the hour is to develop green chemicals or dyes for sustainable textile processing with an eco-friendly approach. In light of above, a bio-colour has been extracted from Bauhinia vahlii bark and applied on the degummed and bleached silk fabric along with a bioacid (citric acid). Dyed silk fabrics were tested for their color strength and fastness properties like color fastness to washing, water crocking and light and found satisfactory results. Banana peduncle extract (BPE) is also applied on the dyed fabric to improve the fastness properties and enhance the functional properties like flame retardant by pad-dry-cure method. Dyed and BPE treated silk fabric was tested and analysed for their color fastness properties and mechanical properties, like thickness, bending length, flexural rigidity and crease recovery and the results were recorded. Notably, evaluation of dyed and BPE treated silk fabric was carried out for flame retardancy according to ASTM D1230 standards and promising result was obtained.
\end{abstract}

Keywords Silk $\cdot$ Bauhinia vahlii bark $\cdot$ Natural dye $\cdot$ Banana peduncle extract $\cdot$ Flame retardant

\section{Introduction}

The textile industry is the major consumer of synthetic dyes used for dyeing and printing of textile material [1]. Synthetic dyes are hazardous, carcinogenic to human body, destroying eco-system and toxic to aquatic biodiversity [2]. Due to the current environmental consciousness, extraction of colorants from natural substrates and its application on textiles has drawn considerable attention in recent past. Several studies were carried out on the extraction of natural dyes and its application on textile material. Demand of natural dyes is increasing continuously as their extraction and application on textile material does not require strong acids and alkalis. Moreover, natural dyes are biodegradable, have wide variety non-toxic, non-carcinogenic, easily available and renewable, eco-friendly; provide a wide range of shades with acceptable levels of color fastness properties [3]. Now, it is the need of the hour to use natural colorants in textile application instead of synthetic dyes. Coloring substances can be extracted from the different parts of the plant like roots, barks, leaves, fruits and flowers and also from the other natural sources. Natural colorants are not only used for their medicinal value and anti-oxidant properties but also to enhance the aesthetic value of the textile product $[4,5]$. Therefore, to address some of these issues this study was aimed to dye silk fabric with eco-friendly natural dye extracted from bark of Bauhinia vahlii plant.

B. vahlii Plant belongs to the class Angiospermae and family Leguminosaceae [6]. It is a giant climber and one of the most abundant Indian Bauhinia species. The plant is distributed in the Sub-Himalayan region and in Assam,

Goutam Bar, goutam.bar@nift.ac.in | 'Department of Textile Design, National Institute of Fashion Technology, Bhubaneswar, India. ${ }^{2}$ Department of Textile Technology, Indian Institute of Technology, Delhi, New Delhi, India. 
Central India, Bihar, Odisha, Eastern and Western Ghats of India. Their leaves and stem barks have been used frequently in folk medicine as remedies for the treatment of diabetes, infections, pains and inflammatory processes and have been confirmed through numerous biological studies $[6,7]$.

B. vahlii bark is composed of ligno cellulose and its aqueous extract contains different phyto constituents, such as alkaloids, carbohydrates, glycosides, saponins, flavonoids and triterpenes, tannins and anthraquinones. Presence of tannins and anthraquinones in B. vahlii bark extract indicates that it can be used as coloring material. $[4,8]$. Most of the natural dyes contain -OH group in their structure and can be esterified with a non-polymeric polycarboxilic acids such as citric acid [5]. In this present study silk fabric is dyed with $B$. vahlii bark extract with citric acid (Fig. 1).

Silk, known as "the queen of fibers" worldwide is an exclusive textile material for its lusture, wearing comfort ability and drapability [9]. Textile materials with different functional properties like flame retardant, antimicrobial is in great demand nowadays and also do value addition to the product. The high nitrogen and sulphur content of silk fabric makes it less flammable than other fibres. However, it still cannot meet the strict compliance of fire safety regulations for flame retardant textile and apparel [10]. Use of synthetic chemicals to impart flame retardant property in the silk fabric retard sustainability of textile processing. Some of the plants contain phosphate, chloride, silicate and other

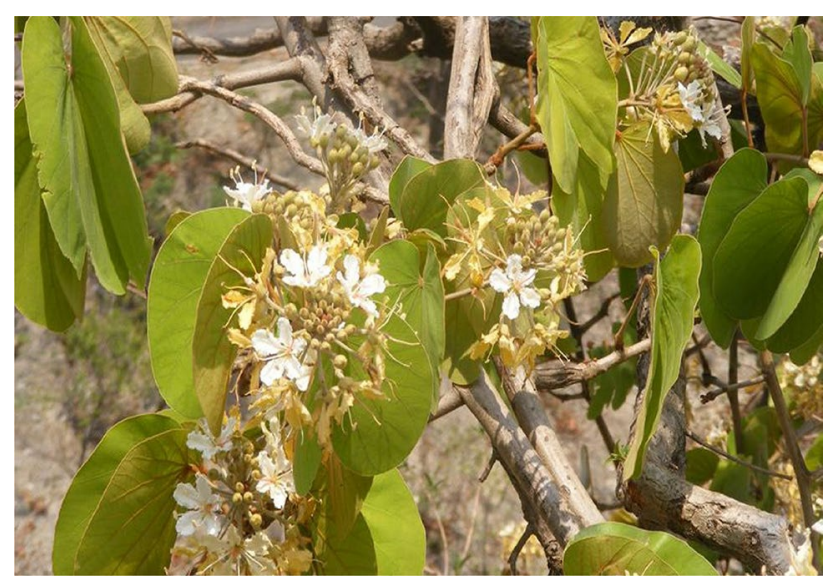

Fig. 1 B. vahlii plant [13] minerals, metal oxides and mineral salts; they have potential to be utilized to impart flame retardancy to the cellulose and other textile materials [11].

In the study developed by Gérard et al. [12], the mineral analysis of the banana peduncle extract revealed the presence of high amount of Nitrogen $(9.6 \mathrm{mg} / \mathrm{g})$, Calcium $(84.67 \mathrm{mg} / 100 \mathrm{~g})$, Sodium $(363.16 \mathrm{mg} / 100 \mathrm{~g})$, potassium $(83.67 \mathrm{mg} / 100 \mathrm{~g})$, Phosphorus $(0.058 \mathrm{mg} / 100 \mathrm{~g})$, iron $(0.077 \mathrm{mg} / 100 \mathrm{~g})$, and magnesium $(39.05 \mathrm{mg} / 100 \mathrm{~g})$. Due to presence of such high mineral content banana peduncle extract has potential to act as a flame retardant. The aim of the present study was to improve the fastness properties of dyed silk fabric and also to impart flame retardant finish, by dyeing the silk fabric with $B$. vahlii bark extract and treated with BPE.

\section{Experimental}

\subsection{Materials}

A 40 GSM silk habutai plain woven fabric was sourced from the local fabric market of Bhubaneswar, India having ends/ inch and picks/inch 120 and 104 and warp and weft yarn count 22 and 55 denier, respectively. B. vahlii bark was collected from Simlipal reserve forest, Odisha, India. Sodium carbonate of Ramken was purchased from Bhubaneswar, India. Lemon juice was collected from fresh lemon purchased from local market. Banana peduncle was sourced from the local farmer of Bhubaneswar.

\subsection{Bark extract of B. vahlii in aqueous medium}

B. vahlii Bark was dried in shed at room temperature for 7-10 days, cut into small pieces and grinded in a home grinding machine. The grinded fibrous powder was soaked in the distilled water for 30 min in 6 different pots with material to liquor ratio 1:20. Anhydrous $\mathrm{Na}_{2} \mathrm{CO}_{3}$ was added in the pots and heated for $2 \mathrm{~h}$ as per the conditions mentioned in the Table 1. Extraction process was carried out in the water bath. Extracts were collected in six different pots by neutralization with citric acid and named as dye solution 1 , dye solution 2 , dye solution 3 , dye solution 4 , dye solution 5 and dye solution 6 according to the pot number. Figure 2 shows the extraction process from collection of bark to drying of the bark and then grinding and extraction in aqueous medium. Figure 3 shows color spectrum of $B$. vahlii bark
Table 1 Temperature and $\mathrm{Na}_{2} \mathrm{CO}_{3}$ concentration for aqueous extraction from $B$. vahlii bark

\begin{tabular}{lllllll}
\hline & Pot 1 & Pot 2 & Pot 3 & Pot 4 & Pot 5 & Pot 6 \\
\hline $\begin{array}{l}\text { Temperature } \\
\mathrm{Na}_{2} \mathrm{CO}_{3} \text { (on the weight } \\
\text { of bark) }\end{array}$ & $\mathrm{Nil}$ & $60{ }^{\circ} \mathrm{C}$ & & & $90{ }^{\circ} \mathrm{C}$ & \\
\hline
\end{tabular}




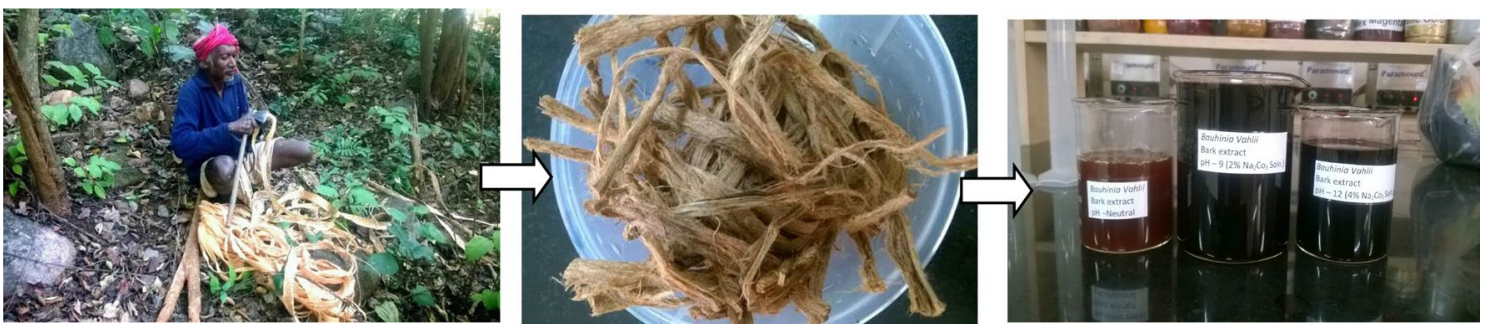

Fig. 2 Bark extract of B. vahlii in aqueous medium from plant to solution [14]

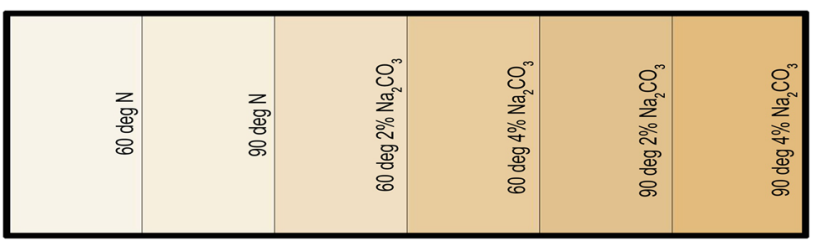

Fig. 3 Color spectrum of $B$. vahlii bark extract in aqueous medium (spectrophotometer images). Note: deg degree Celsius, $N$ Neutral $\mathrm{pH}, \% \mathrm{Na}_{2} \mathrm{CO}_{3}$ sodium carbonate aqueous solution (weight/volume)

extract dye solutions in spectrophotometer. Difference in coloring substance concentration is clearly visible from the color spectrum.

\subsection{Application of dyes}

Degummed and bleached silk fabric was dyed with all the six dye solutions extracted from $B$. vahlii bark in different temperature as mentioned in Table 2. Extracted solutions were used directly without any dilution, having material to liquor ratio 1:30. Dyeing was carried out on paramount water bath without any mordanting agent for $1 \mathrm{~h}$. $\mathrm{pH}$ of the bath was adjusted to 2 by using citric acid i.e. lemon juice. Dyed samples were rinsed with cold and hot water to remove the superficial dyes. Total 12 samples were developed from the 6 different dye solutions.

\subsection{Extraction process of banana peduncle extract}

Collected Banana peduncle was cleaned and washed properly with running water and cut into pieces of 15 to 18 inches. Peduncle pieces were further sliced lengthwise having 2 to $3 \mathrm{~mm}$ in thickness and passed through Laboratory Padding Mangle. Banana peduncle extract was collected from the padding mangle tray and stored in a container. The $\mathrm{pH}$ of the BPE was 5.35 at the time of extraction.

\subsection{Application of banana peduncle extract}

To improve the fastness properties and also to enhance the functional properties i.e. flame retardancy of the dyed fabric, sample number 11 was chosen and treated with Banana peduncle extract with pad-dry-cure method. Dyed fabric sample was impregnated in the banana peduncle extract and passed through the padding mangle to remove the excess solution and also to control the add-on percentage of the banana peduncle extract. The sample was dried for $5 \mathrm{~min}$ at $80^{\circ} \mathrm{C}$ and then cured at $140^{\circ} \mathrm{C}$ for $3 \mathrm{~min}$.

The weight gain \% i.e. percentage increase in sample weight was calculated as per the following equation.

Weight gain $\%=\left[\left(\mathrm{W}_{2}-\mathrm{W}_{1}\right) / \mathrm{W}_{1}\right] \times 100 \ldots \ldots \ldots \ldots$ for silk fabric dyed with BV bark extract

Weight gain $\%=\left[\left(\mathrm{W}_{3}-\mathrm{W}_{1}\right) / \mathrm{W}_{1}\right] \times 100 \ldots \ldots \ldots \ldots$ for dyed silk fabric treated with BPE

where $W_{3}, W_{2}$ AND $_{1}$ are the oven dry weight of dyed silk fabric treated with $B P E$, silk fabric dyed with $B$. vahlii bark extract and control silk fabric, respectively [10].

Table 2 Dyeing temperature using different dye solutions

\begin{tabular}{lllllll}
\hline Temperature & Dye solution 1 & Dye solution 2 & Dye solution 3 & Dye solution 4 & Dye solution 5 & Dye solution 6 \\
\hline Room temp. & $\checkmark$ & $\checkmark$ & $\checkmark$ & $\checkmark$ & $\checkmark$ & $\checkmark$ \\
$60^{\circ} \mathrm{C}$ & $\checkmark$ & $\checkmark$ & $\checkmark$ & $\checkmark$ & $\checkmark$ & $\checkmark$ \\
$90^{\circ} \mathrm{C}$ & & & & & $\checkmark$ & $\checkmark$ \\
\hline
\end{tabular}




\section{Measurement}

\subsection{Color strength}

Color strength of the $B$. vahlii bark extracts in aqueous medium were measured in Xrite color i7 Spectrophotometer in transmittance mode. The silk fabric samples dyed with $B$. vahlii bark extracts in different conditions were also checked for their color strength with the help of the same spectrophotometer in reflectance mode.

\subsection{Fastness properties}

Silk fabric samples dyed with $B$. vahlii bark extracts were tested for their colorfastness properties. Samples were tested for colorfastness to washing, Water, crocking and light as per the ISO 105 C06, ISO 105 E01, ISO 105 X12 and ISO 105 B02 respectively.

\subsection{Flammability assessment}

Control silk fabric, dyed silk fabric (sample no 11), undyed silk fabric treated with BPE and dyed silk fabric (sample no 11) treated with BPE were tested for their response to heat and flame under controlled condition. Here sample no 11 was selected randomly for BPE treatment and further flammability assessment. All the Samples were tested for flammability in Digiflame, $45^{\circ}$ flammability tester of Paramount as per ASTM D1230. 10 samples were tested for each category. Samples size were $150 \mathrm{~mm} \times 50 \mathrm{~mm}$. Flame spread time, burning rate and char length were measured during testing.

\subsection{Mechanical properties}

Silk fabric dyed with $B$. vahlii bark extract and silk fabric dyed with B. vahlii bark extract and treated with BPE were tested for their mechanical properties like thickness, bending length, flexural rigidity and crease recovery. Testing was conducted inside institute's laboratory under standard atmospheric condition.

\section{Results and discussion}

\subsection{Bark extracts color strength}

Table 3 shows the percentage color strength of $B$. vahlii bark extract, in aqueous medium and the data reveals that there is a remarkable increase in color strength, with increase in extraction temperature and $\mathrm{pH}$ of the bath. Color strength value was increased up to $760 \%$, when extraction was done at $90^{\circ} \mathrm{C}$ with $4 \% \mathrm{Na}_{2} \mathrm{CO}_{3}$ as compared to extraction at $60^{\circ} \mathrm{C}$ in neutral condition. It is also clear from the table that percentage color strength of the $B$. vahlii bark extract is directly proportional to the extraction temperature and $\mathrm{Na}_{2} \mathrm{CO}_{3}$ concentration of the extraction bath. This was happened may be due to presence of lignocelluloses in the $B$. vahlii bark. Figure 4 shows that sol $^{\mathrm{n}} 1(60 \mathrm{deg} \mathrm{N})$ transmit maximum light through the dye solution as it is the lightest one among all. Whereas sol ${ }^{\text {n }}$ 6 transmit very less amount of light through the solution due to presence of more coloring material in the solution as compared to others.

\subsection{Color strength of dyed sample}

Figure 5 shows the samples, dyed with different extract solutions in different temperature to get wide range of shades, when applied on silk fabric in exhaust method. It is clear from the images that the dyed samples are very bright in color and lustrous, which can be converted into attractive products for practical application. Percentage color strength of all the dyed samples was measured in spectrophotometer and the results are tabulated in

Table 3 Percentage color strength of $B$. vahlii bark extracts in aqueous medium

\begin{tabular}{|c|c|c|c|c|c|c|c|}
\hline Sol $^{n}$ no & Standard name & $L^{*}$ & & $a^{*}$ & $b^{*}$ & $c^{*}$ & $h^{\circ}$ \\
\hline \multirow[t]{2}{*}{1} & $60 \operatorname{deg} N$ & 97.58 & & -0.07 & 5.22 & 5.22 & 90.8 \\
\hline & Trial name & $\mathrm{DL}^{*}$ & $\mathrm{Da}^{*}$ & $\mathrm{Db}^{*}$ & $D C^{*}$ & $\mathrm{DH}^{*}$ & \%STR-SWL \\
\hline 4 & $90 \operatorname{deg} N$ & $-1.52 \mathrm{D}$ & $0.55 \mathrm{R}$ & $4.29 \mathrm{Y}$ & $4.30 \mathrm{~B}$ & $-0.45 R$ & 166.95 \\
\hline 2 & 60 deg $2 \% \mathrm{Na}_{2} \mathrm{CO}_{3}$ & $-7.02 \mathrm{D}$ & $2.41 \mathrm{R}$ & $10.79 Y$ & $10.96 \mathrm{~B}$ & $-1.46 R$ & 292.45 \\
\hline 3 & 60 deg $4 \% \mathrm{Na}_{2} \mathrm{CO}_{3}$ & $-13.46 \mathrm{D}$ & $5.24 \mathrm{R}$ & $21.86 Y$ & $22.35 \mathrm{~B}$ & $-2.43 \mathrm{R}$ & 491.92 \\
\hline 5 & 90 deg $2 \% \mathrm{Na}_{2} \mathrm{CO}_{3}$ & $-17.03 \mathrm{D}$ & $5.95 \mathrm{R}$ & $25.08 \mathrm{Y}$ & $25.64 \mathrm{~B}$ & $-2.60 R$ & 642.22 \\
\hline 6 & 90 deg $4 \% \mathrm{Na}_{2} \mathrm{CO}_{3}$ & $-19.23 \mathrm{D}$ & $9.31 \mathrm{R}$ & $31.82 Y$ & $32.96 \mathrm{~B}$ & $-3.64 R$ & 760.42 \\
\hline
\end{tabular}

Sol ${ }^{n}$ no dye solution, $L^{*}$ value of lightness and darkness, $a^{*}$ value of red and green, $b^{*}$ value of yellow and blue, $c^{*}$ value of chroma, $h^{\circ}$ value of hue, $D L^{*}$ difference in lightness and darkness, $D a^{*}$ difference in red and green, $D b^{*}$ difference in yellow and blue, $D C^{*}$ difference in chroma, $D H^{*}$ difference in hue, \%STR-SWL single wavelength strength percentage 
Fig. 4 Percentage transmittance curve of $B$. vahlii bark extracts in aqueous medium

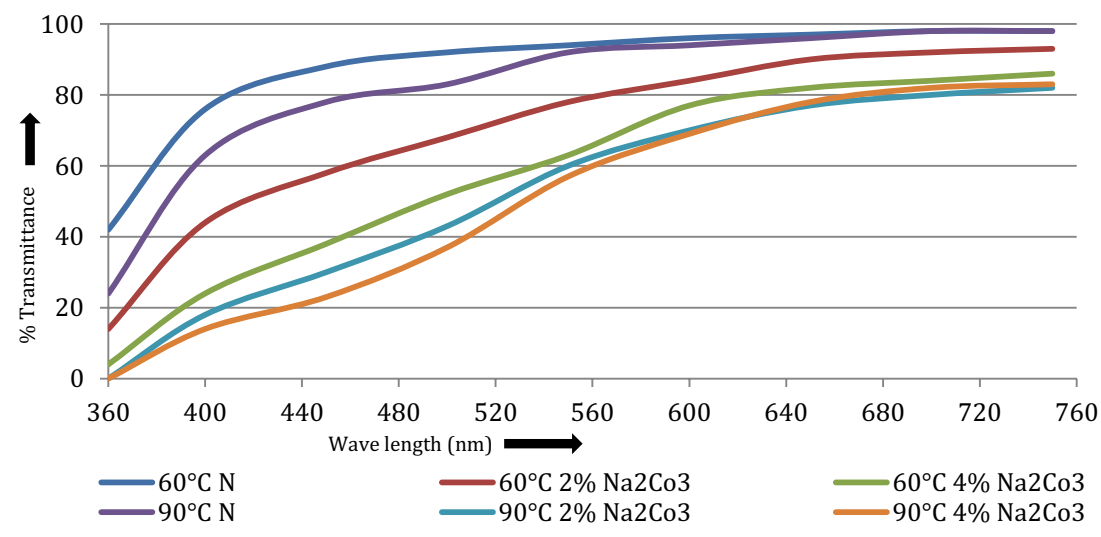

Silk Fabric samples dyed with Bauhinia Vahlii Bark Extract
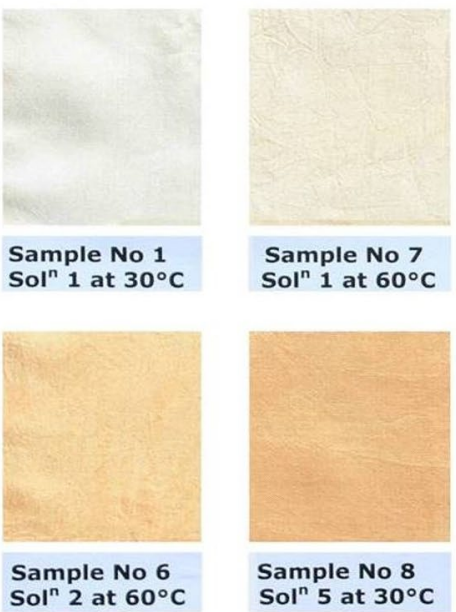
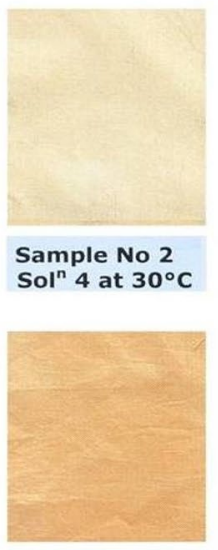

Sample No 10 $\mathrm{Sol}^{\mathrm{n}} 4$ at $90^{\circ} \mathrm{C}$

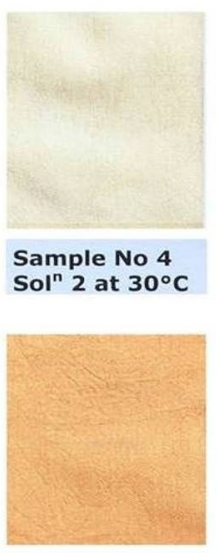

Sample No 9 $\mathrm{Sol}^{\mathrm{n}} 3$ at $60^{\circ} \mathrm{C}$

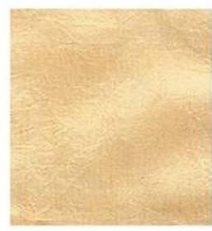

Sample No 3 $\mathrm{Sol}^{\mathrm{n}} 3$ at $30^{\circ} \mathrm{C}$

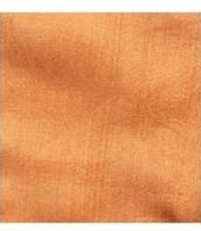

Sample No 11 $\mathrm{Sol}^{\mathrm{n}} 5$ at $90^{\circ} \mathrm{C}$

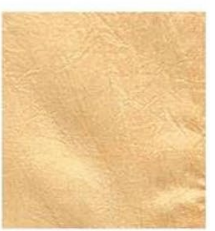

Sample No 5 $\mathrm{Sol}^{\mathrm{n}} 6$ at $30^{\circ} \mathrm{C}$

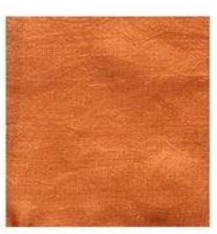

Sample No 12 Sol $^{\mathrm{n}} 6$ at $90^{\circ} \mathrm{C}$

Fig. 5 Silk fabric samples dyed with B. vahlii bark extract in different temperature

Table 4. Results show that there is remarkable improvement in shade depth. Data indicate that sample no 12 is $400 \%$ darker than the sample no 1 . Moreover, data also shows that the shade depth is increased from first to last sample uniformly.

\subsection{Fastness properties}

Table 5 illustrates the color fastness properties of silk fabric samples dyed with $B$. vahlii bark extracts. Out of 12 samples, 3 samples were selected on basis of shade depth for the testing purpose. Sample number 1 exhibits excellent result in color fastness to washing, water and crocking. However, sample shows moderate result in colorfastness to light test, may be due to its lower shade depth. Sample number 5 evidences very good results against all tests. In case of sample number 11 , color change in washing gives moderate result, though it is accepted as per the international standards. Other results are very much accepted as per the standard norms.

Table 6 demonstrates the improvement in color fastness properties of sample number 11 after BPE treatment against its original sample. Results show that there is significant improvement in fastness properties.

\subsection{Flammability test}

Table 7 shows the weight gain percentage of dyed and BPE treated fabric as well as $45^{\circ}$ flammability test results. Weight of the dyed silk fabric is increased by $2.63 \%$, whereas dyed and BPE treated silk fabric gain $7.89 \%$ weight compared to the control silk fabric. Flammability testing has been done as per ASTM D1230 of control silk fabric, silk fabric dyed with $B$. vahlii bark extract, undyed silk fabric treated with BPE extract and silk fabric dyed with B. vahlii extract and treated with BPE. Flame spread time data of control silk fabric and dyed silk fabric indicate that, 
Table 4 Percentage color strength of silk fabrics dyed with B. vahlii bark extract

\begin{tabular}{|c|c|c|c|c|c|c|c|c|}
\hline Sample no & Standard name & $L^{*}$ & & $a^{*}$ & & & $C^{*}$ & $\mathrm{~h}^{\circ}$ \\
\hline \multirow[t]{2}{*}{1} & $60 \mathrm{deg} N$ Cold & \multicolumn{2}{|c|}{85.97} & \multicolumn{2}{|l|}{1.86} & 4.54 & \multirow{2}{*}{$\frac{4.9}{\text { CV-SWL }}$} & \multirow{2}{*}{$\begin{array}{r}67.74 \\
\text { STTR-SWL }\end{array}$} \\
\hline & Trial name & $\mathrm{DL}^{*}$ & $\mathrm{Da}^{*}$ & $\mathrm{Db}^{*}$ & $\mathrm{DC}^{*}$ & $\mathrm{DH}^{*}$ & & \\
\hline 7 & 60 deg N/60 deg & $-1.78 \mathrm{D}$ & $1.92 \mathrm{R}$ & $3.32 \mathrm{Y}$ & $3.81 \mathrm{~B}$ & $-0.39 R$ & 1.019 & 114.51 \\
\hline 2 & $90 \mathrm{deg} N /$ Cold & $-2.35 \mathrm{D}$ & $0.47 \mathrm{R}$ & $4.67 \mathrm{Y}$ & $4.59 \mathrm{~B}$ & $0.96 \mathrm{G}$ & 1.235 & 138.83 \\
\hline 4 & 60 deg $2 \% \mathrm{Na}_{2} \mathrm{CO}_{3} /$ Cold & $-5.07 \mathrm{D}$ & $2.83 \mathrm{R}$ & $8.15 \mathrm{Y}$ & $8.62 \mathrm{~B}$ & $0.28 \mathrm{G}$ & 1.235 & 138.83 \\
\hline 3 & 60 deg $4 \% \mathrm{Na}_{2} \mathrm{CO}_{3} /$ Cold & $-6.71 \mathrm{D}$ & $5.16 \mathrm{R}$ & $11.60 \mathrm{Y}$ & $12.7 \mathrm{~B}$ & $-0.20 \mathrm{R}$ & 1.3 & 146.11 \\
\hline 5 & 90 deg $4 \% \mathrm{Na}_{2} \mathrm{CO}_{3} /$ Cold & $-8.35 \mathrm{D}$ & $6.22 \mathrm{R}$ & $10.59 \mathrm{Y}$ & $12.24 \mathrm{~B}$ & $-0.94 R$ & 1.512 & 170 \\
\hline 6 & $60 \mathrm{deg} 2 \% \mathrm{Na}_{2} \mathrm{CO}_{3} / 60 \mathrm{deg}$ & $-12.07 \mathrm{D}$ & $6.44 \mathrm{R}$ & $9.78 \mathrm{Y}$ & $11.64 \mathrm{~B}$ & $-1.23 R$ & 1.652 & 185.65 \\
\hline 8 & 90 deg $2 \% \mathrm{Na}_{2} \mathrm{CO}_{3} /$ Cold & $-7.49 \mathrm{D}$ & $3.44 \mathrm{R}$ & $10.56 \mathrm{Y}$ & $11.10 \mathrm{~B}$ & $0.45 \mathrm{G}$ & 1.659 & 186.5 \\
\hline 13 & $90 \mathrm{deg} \mathrm{N} / 90 \mathrm{deg}$ & $-12.40 \mathrm{D}$ & $6.21 \mathrm{R}$ & $11.65 \mathrm{Y}$ & $13.19 \mathrm{~B}$ & $-0.69 R$ & 1.804 & 202.76 \\
\hline 9 & $60 \mathrm{deg} 4 \% \mathrm{Na}_{2} \mathrm{CO}_{3} / 60 \mathrm{deg}$ & $-15.94 \mathrm{D}$ & $9.91 \mathrm{R}$ & $14.80 \mathrm{Y}$ & $17.73 \mathrm{~B}$ & $-1.67 R$ & 2.064 & 231.98 \\
\hline 11 & $90 \mathrm{deg} 2 \% \mathrm{Na}_{2} \mathrm{CO}_{3} / 90 \mathrm{deg}$ & $-23.84 \mathrm{D}$ & $10.88 \mathrm{R}$ & $17.05 \mathrm{Y}$ & 20.16 B & $1.60 \mathrm{R}$ & 3.458 & 388.75 \\
\hline 12 & 90 deg $4 \% \mathrm{Na}_{2} \mathrm{CO}_{3} / 90 \mathrm{deg}$ & $-24.83 \mathrm{D}$ & $12.20 \mathrm{R}$ & $18.24 \mathrm{Y}$ & $21.86 \mathrm{~B}$ & $-1.88 R$ & 3.642 & 409.37 \\
\hline
\end{tabular}

Cold room temperature

Table 5 Color fastness properties of silk fabric dyed with $B$. vahlii bark extract

\begin{tabular}{|c|c|c|c|c|c|c|c|}
\hline \multirow[t]{2}{*}{$\begin{array}{l}\text { Sample } \\
\text { number }\end{array}$} & \multicolumn{2}{|c|}{ Color fastness to washing } & \multicolumn{2}{|c|}{ Color fastness to water } & \multicolumn{2}{|c|}{$\begin{array}{l}\text { Color fastness } \\
\text { to crocking }\end{array}$} & \multirow{2}{*}{$\begin{array}{l}\text { Color } \\
\text { fastness to } \\
\text { light }\end{array}$} \\
\hline & Color change & $\begin{array}{l}\text { Staining on } \\
\text { wool }\end{array}$ & Color change & $\begin{array}{l}\text { Staining on } \\
\text { wool }\end{array}$ & Dry & Wet & \\
\hline 1 & $4-5$ & 5 & $4-5$ & 5 & 5 & 5 & 5 \\
\hline 5 & 4 & $4-5$ & $4-5$ & $4-5$ & 5 & 4 & 6 \\
\hline 11 & $3-4$ & 4 & 4 & 4 & $4-5$ & 4 & 6 \\
\hline
\end{tabular}

Table 6 Color fastness properties of silk fabric dyed with B. vahlii bark extract and treated with BPE

\begin{tabular}{|c|c|c|c|c|c|c|c|}
\hline \multirow[t]{2}{*}{ Sample number } & \multicolumn{2}{|c|}{ Color fastness to washing } & \multicolumn{2}{|c|}{ Color fastness to water } & \multicolumn{2}{|c|}{$\begin{array}{l}\text { Color fastness } \\
\text { to crocking }\end{array}$} & \multirow[t]{2}{*}{ Color fastness to light } \\
\hline & Color change & Staining on wool & Color change & Staining on wool & Dry & Wet & \\
\hline 11 & 4 & 4 & $4-5$ & $4-5$ & 5 & $4-5$ & 7 \\
\hline
\end{tabular}

there is hardly any significant difference in terms of their flammability properties. Average burning times were 5.1 and $5.3 \mathrm{~s}$ in case of control silk fabric and dyed silk fabric respectively. Whereas the standard deviations were 0.36 and $0.52 \mathrm{~s}$ in case of control silk fabric and dyed silk fabric respectively. However, char of dyed fabric indicates that the resistance against burning compared to control fabric as evidence in Figs. 6 and 7.

Dyed silk fabric treated with BPE and undyed fabric treated with BPE extract exhibit excellent performance against flame. Samples did not ignite and left an average char length of 34 and $42 \mathrm{~mm}$ respectively as mentioned earlier with standard deviation 2.79 and $3.01 \mathrm{~mm}$. Dyed and BPE treated silk fabric samples showed great result in all the cases and Fig. 8 proclaim the same. It is also clear from the image that char looks uneven and wavy, which is clearly indicating the burning resistance. This may be due to mineral present in the BPE extract. Though all the flammability test results come under Class I category of ASTM D1230 and considered by trade to be acceptable, dyed and undyed silk fabric treated with BPE evidenced excellent result.

\subsection{Mechanical properties}

Compression test results in Table 8 indicate that there is an increase in fabric thickness due to dyeing with $B$. vahlii bark extract and after treatment with BPE. Bending length and Flexural rigidity test results indicate that the silk fabric dyed with B. vahlii bark extract have better 
Table 7 Flammability of silk fabric after dyeing and finishing

\begin{tabular}{lllll}
\hline Samples & $\begin{array}{l}\text { Weight gain } \\
(\%)\end{array}$ & $\begin{array}{l}\text { Flame } \\
\text { spread } \\
\text { time }(\mathrm{s})\end{array}$ & $\begin{array}{l}\text { Char } \\
\text { length } \\
(\mathrm{mm})\end{array}$ & $\begin{array}{l}\text { Burn- } \\
\text { ing rate } \\
(\mathrm{mm} / \mathrm{s})\end{array}$ \\
\hline $\begin{array}{l}\text { Control silk } \\
\text { fabric }\end{array}$ & - & 5.1 & $\mathrm{BEL}$ & 27.45 \\
$\begin{array}{l}\text { Dyed silk fabric } \\
\begin{array}{l}\text { Undyed silk } \\
\text { fabric treated }\end{array}\end{array}$ & 2.63 & 5.3 & $\mathrm{BEL}$ & 26.41 \\
$\begin{array}{l}\text { with banana } \\
\text { peduncle } \\
\text { extract }\end{array}$ & $\mathrm{DNI}$ & 42 & - \\
$\begin{array}{l}\text { Dyed silk fabric } \\
\text { treated with } \\
\text { banana }\end{array}$ & 7.89 & & & \\
peduncle & & $\mathrm{DNI}$ & 34 & - \\
extract & & & \\
\hline
\end{tabular}

$D N I$ do not ignite, $B E L$ burn entire length

handle properties than the control silk fabric in both warp and weft wise direction. This may be due mechanical agitation during dyeing process and due to the presence of different phyto chemicals in the $B$. vahlii bark extract. Dyed silk fabric treated with BPE shows better handle properties in terms of their bending length and flexural rigidity in warp wise compared to control and dyed silk fabric sample. However, in weft wise direction, it shows higher bending length and flexural rigidity. Crease recovery result shows that there is no significant difference between the samples.

\section{Conclusion}

B. vahlii bark extract is a very good source of natural dye. Color yield percentage from the bark will increase in higher temperature and higher alkaline $\mathrm{pH}$ due to presence of lingo-cellulose in the bark. Silk fabric dyed with $B$. vahlii bark extract gives very bright color and wide range of shades. Silk fabric dyed with B. vahlii bark extract shows very good results against color fastness to washing, water, crocking and light test. Fastness properties were further when dyed silk fabric treated with BPE extract.
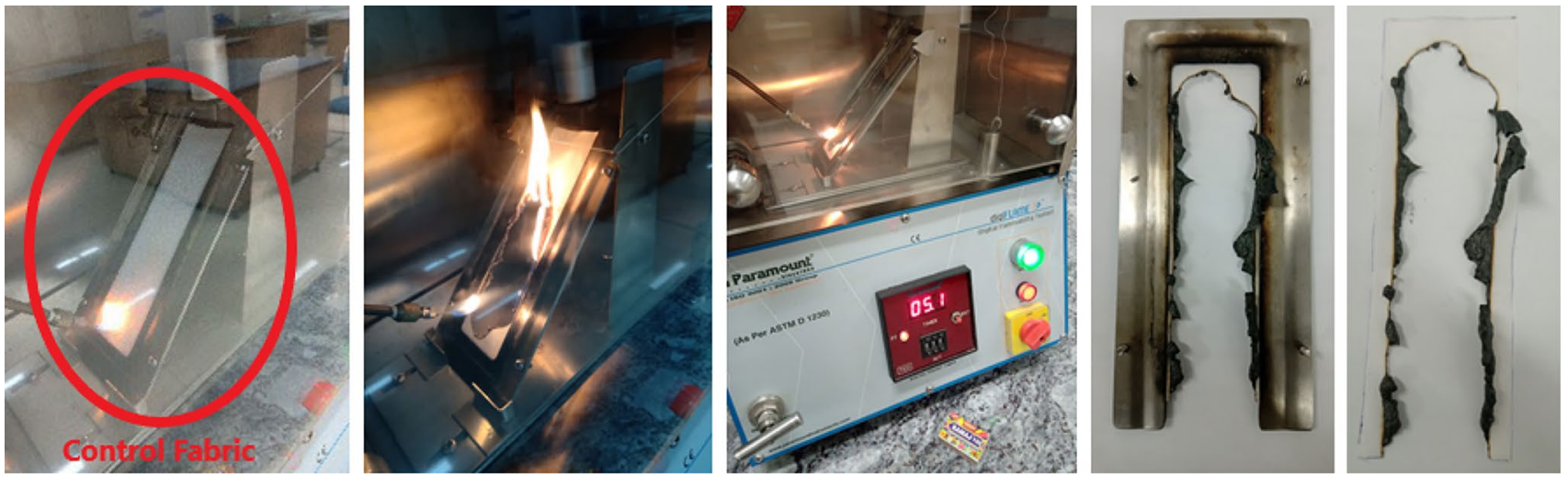

Fig. 6 Flammability images of control silk fabric
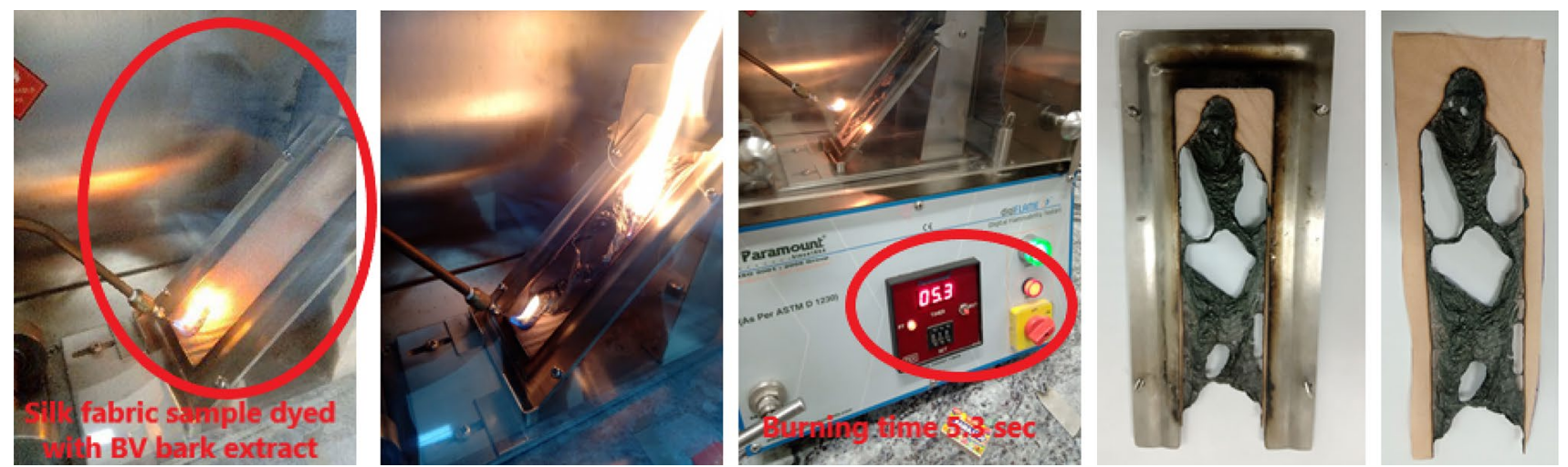

Fig. 7 Flammability images of silk fabric dyed with B. vahlii bark extract 

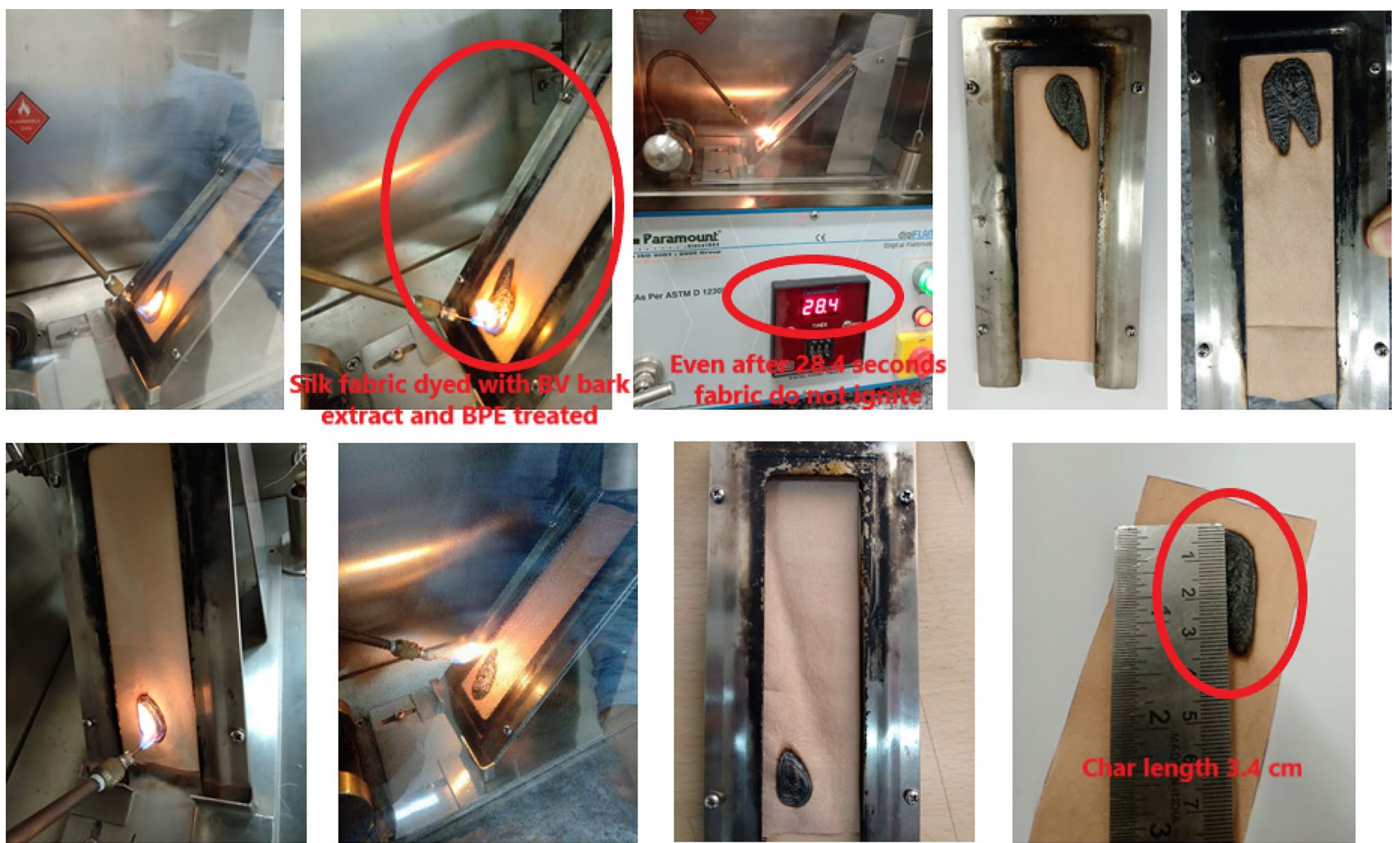

Fig. 8 Flammability images of silk fabric dyed with B. vahlii bark extract and treated with BPE

Table 8 Compression and bending properties of silk fabric after dyeing and finishing

\begin{tabular}{|c|c|c|c|c|c|c|c|c|}
\hline & \multirow[t]{2}{*}{$\begin{array}{l}\text { Surface } \\
\text { thickness } \\
(\mathrm{mm})\end{array}$} & \multirow[t]{2}{*}{$\begin{array}{l}\text { Fabric } \\
\text { weight }(\mathrm{g} / \\
\left.\mathrm{cm}^{2}\right)\end{array}$} & \multicolumn{2}{|c|}{$\begin{array}{l}\text { Bending } \\
\text { length }(\mathrm{cm})\end{array}$} & \multicolumn{2}{|c|}{$\begin{array}{l}\text { Flexural } \\
\text { rigidity } \\
(\mathrm{mg} \mathrm{cm})\end{array}$} & \multicolumn{2}{|c|}{$\begin{array}{l}\text { Crease } \\
\text { recovery } \\
\text { angle } \\
\text { (degree) }\end{array}$} \\
\hline & & & Warp & Weft & Warp & Weft & Warp & Weft \\
\hline Control silk fabric & 0.09 & 0.0038 & 1.90 & 2.03 & 26.06 & 31.79 & 97 & 103 \\
\hline Dyed silk fabric & 0.11 & 0.0039 & 1.78 & 1.79 & 22.00 & 22.36 & 94 & 102 \\
\hline Undyed silk fabric treated with BPE & 0.11 & 0.0040 & 1.88 & 2.08 & 26.57 & 35.99 & 96 & 105 \\
\hline Dyed fabric treated with BPE & 0.12 & 0.0041 & 1.65 & 2.15 & 18.41 & 40.74 & 92 & 105 \\
\hline
\end{tabular}

BPE treated silk fabric exhibit excellent performance in $45^{\circ}$ flammability test. Sample did not ignite during the test and left average char length of $34 \mathrm{~mm}$. After dyeing with $B$. vahlii bark extracts fabric shows better handle properties. Whereas after BPE treatment fabric shows warp wise lower bending length and flexural rigidity and weft wise more. Crease Recovery result is found satisfactory and within the acceptable limit.

\section{Compliance with ethical standards}

Conflict of interest The authors declare that they have no conflict of interest. 


\section{References}

1. Sudha M, Saranya A, Selvakumar G, Sivakumar N (2014) Microbial degradation of azo dyes: a review. Int J Curr Microbiol Appl Sci 3:670-690

2. Dan'Azumi S, Bichi M (2010) Industrial pollution and heavy metals profile of Challawa river in Kano, Nigeria. J Appl Sci Environ Sanit 5:56-62

3. Tayade SV, Pandey S, Giri ASG (2015) A review: importance of natural dyes from Solanum xanthocarpum. Int J Sci Eng Res 6(12):33-37

4. Teklemedhin TB, Gopalakrishnan LH (2018) Environmental friendly dyeing of silk fabric with natural dye extracted from Cassia singueana plant. J Text Sci Eng S3-001:1-6

5. Das D, Datta DB, Bhattacharya P (2014) Simultaneous dyeing and finishing of silk fabric with natural color and itaconic acid. Cloth Text Res J 32(2):93-106

6. Chauhan R, Saklani S (2013) Bauhinia vahlii; plant to be explored. Int Res J Pharm 4(8):5-9

7. Elbanna AH, Mahroua EA, Khaleel AE, El-alfy TS (2016) Morphological and anatomical features of Bauhinia vahlii Wright \& Arnoot. Grown in Egypt. J Appl Pharm Sci 6(12):84-93

8. Chavan RT, Kadam AS (2012) Preliminary phytochemistry and antimicrobial activity of bark of Bauhinia racemosa Lamk. Curr Bot 3(4):31-33

9. Guan J, Lu H, Chen Y (2013) Apparel performance of flame retardant silk fabrics. J Eng Fibers Fabr 8(4):30-34
10. Zhang QH, Zhang W, Chen GQ, Xing TL (2016) Flame retardant finish of silk fabric with dimethyl phosphonate doped silica sol. In: 2nd annual international conference on advanced material engineering (AME 2016), Atlantis Press, pp 877-883

11. Basak S, Samanta KK, Chattopadhyay SK, Saxena S, Narkar R (2018) Banana pseudostem sap and boric acid-a new green intumescent for making self-extinguishing cotton fabric. Indian J Fibre Text Res 43:36-43

12. Gérard NN, Cedric KV, Macaire WH (2014) Physicochemical and mineral composition of dessert banana peduncle juice during conservation at ambient temperature. Greener J Agric Sci 4(8):326-337

13. Medicinal Plants: Bauhinia vahlii Phanera vahlii Mahul Addachettu (2012) www.medplants.blogspot.com. http://www. medplants.blogspot.com/2012/07/bauhinia-vahlii-bauhiniaracemosa.html

14. Kukreti Ishan (2018) Habitat rights of Odisha's tribal group denied; their livelihood also at stake. www.downtoearth.org. in. https://www.downtoearth.org.in/news/forests/habitatrights-of-odisha-s-tribal-group-denied-despite-district-s-appro val-59428

Publisher's Note Springer Nature remains neutral with regard to jurisdictional claims in published maps and institutional affiliations. 